\title{
WILEY-VCH
}

DOI: $10.1002 /($ please add manuscript number $))$

Article type: Communication

\section{Surface Passivation of CIGS Solar Cells using Gallium Oxide}

Siddhartha Garud ${ }^{1,2}$, Nikhil Gampa ${ }^{1}$, Thomas G. Allen ${ }^{3}$, Ratan Kotipalli ${ }^{4}$, Denis Flandre ${ }^{4}$, Maria Batuk ${ }^{5}$, Joke Hadermann ${ }^{5}$, Marc Meuris ${ }^{7,8}$, Jef Poortmans ${ }^{1,6,7}$, Arno Smets ${ }^{2}$, Bart Vermang ${ }^{7,9^{*}}$

S.Garud, N. Gampa, T.G. Allen, Dr. R. Kotipalli, Prof. D. Flandre, Dr. M. Batuk ${ }^{5}$, Prof. J. Hadermann, Dr. M. Meuris, Prof. J. Poortmans, Prof. A.H.M. Smets, Prof. B. Vermang

1 imec- partner in Solliance, 3000, Leuven, Belgium

2 Delft University of Technology, 2628 CD, Delft, The Netherlands

3 Australian National University, Canberra ACT 0200, Australia

4 Université catholique de Louvain, ICTEAM Institute, 1348 Louvain-la-Neuve, Belgium

5 University of Antwerp, Groenenborger Groenenborgerlaan 171, 2020 Antwerp, Belgium

6 Department of Electrical Engineering (ESAT), KU Leuven, 3001, Leuven, Belgium

7 imec division IMOMEC - partner in Solliance, 3590, Hasselt, Belgium

8 Institute for Material Research (IMO) Hasselt University, 3590, Hasselt, Belgium

9 Faculty of engineering technology, Hasselt University, 3590, Hasselt, Belgium

E-mail: bart.vermang@uhasselt.be

Prof. Dr. Bart Vermang

Faculty of engineering technology, Hasselt University, 3590, Hasselt, Belgium

Keywords: CIGS solar cells; surface passivation; gallium oxide; plasma-enhanced atomic layer deposition

This work proposes gallium oxide grown by plasma-enhanced atomic layer deposition, as a surface passivation material at the $\mathrm{CdS}$ buffer interface of $\mathrm{Cu}(\mathrm{In}, \mathrm{Ga}) \mathrm{Se}_{2}$ (CIGS) solar cells. In preliminary experiments, a metal-insulator-semiconductor (MIS) structure is used to compare aluminium oxide, gallium oxide and hafnium oxide as passivation layers at the CIGS-CdS interface. The findings suggest that Gallium oxide on CIGS may show a density of positive charges and qualitatively, the least interface trap density. Subsequent solar cell results with an estimated $0.5 \mathrm{~nm}$ passivation layer show an substantial absolute improvement of $56 \mathrm{mV}$ in open-circuit voltage $\left(V_{O C}\right), 1 \mathrm{~mA} / \mathrm{cm}^{2}$ in short-circuit current density $\left(J_{S C}\right)$, and $2.6 \%$ in overall efficiency as compared to a reference (with the reference showing $8.5 \%$ under AM 1.5G). 


\section{WILEY-VCH}

\section{Introduction}

$\mathrm{Cu}(\mathrm{In}, \mathrm{Ga})(\mathrm{S}, \mathrm{Se})_{2}$ solar cells of the chalcopyrite crystal structure have been one of the champions of thin-film technologies, with record laboratory efficiencies reaching $22.6 \%$. ${ }^{[1]}$ High power conversion efficiencies in crystalline silicon solar cells have been achieved through the invention of complex cell architectures such as PERC (passivated emitter and rear cell). Passivation of the top and rear surfaces and the formation of low resistance contacts cutting through these passivation layers, have been key aspects of high-efficiency silicon solar cell architectures. The $22.6 \%$ record efficiency in CIGS solar cells required a treatment of the top absorber surface with Rubidium fluoride (RbF). Positive effects have also been observed with sodium, potassium and rubidium. ${ }^{[1,2]}$ Collectively, they provide new evidence for the role of the CIGS/CdS interface as a limiting factor for high efficiencies. The goal of the work presented in this publication was to introduce a passivation layer between CIGS and CdS and to reduce recombination at this interface in a reproducible manner. An analysis has been presented for the potential of gallium oxide deposited by plasma-enhanced atomic layer deposition, as a passivation layer at the CIGS-CdS interface. A schematic of the cell architecture is shown in

\section{Figure 1 (a).}

Passivation layers can reduce recombination at a surface and lead to an improvement in opencircuit voltage $\left(V_{O C}\right)$ as well as better charge collection (visible in $E Q E$ and $J_{S C}$ ). ${ }^{[3,4,5]}$ This can be due to a 'chemical passivation' which reduces dangling bonds and active interface defects. It may also be due to a 'field-effect passivation' which can, based on the polarity of charges in the region, either repel minority charge carriers and reduce recombination or repel majority carriers sufficiently to cause an inversion at the surface. ${ }^{[6,7]}$

$\mathrm{Al}_{2} \mathrm{O}_{3}$ passivation layers have been recently demonstrated on CIGS solar cells between the CIGS-Mo back contact interface. ${ }^{[8,9]}$ At the front interface, CIGS solar cells have often featured buffer layers between the TCO and CIGS absorber. CdS is most commonly used for the band- 


\section{WILEY-VCH}

alignment at this interface. Another layer such as $\mathrm{i}-\mathrm{ZnO}$ is used on top of $\mathrm{CdS}$ to reduce shunts and maintain electrical homogeneity. However, CdS creates parasitic absorption below $550 \mathrm{~nm}$ wavelength of irradiation and $\mathrm{Cd}$ is well-known for its toxicity. Koida et al., have recently investigated $a-\operatorname{In}_{2-2 x} \mathrm{Ga}_{2 x} \mathrm{O}_{3}$ as suitable buffer layers with $\mathrm{x}=0.9$ and $\mathrm{x}=1$ giving the most promising results ${ }^{[10]}$ The $V_{O C}$ values obtained were comparable to the reference $V O C$ with a i$\mathrm{ZnO} / \mathrm{CdS}$ buffer layer, but the FF values were lower. These effects were primarily attributed to a positive conduction band offset which also led to the formation of a secondary barrier and reducing charge collection in forward bias voltages. The height of such a barrier can be reduced by decreasing the thickness of the buffer layer or by increasing the $\mathrm{n}$-type doping in it. Hence, a- $\mathrm{GaO}_{\mathrm{x}}$ with thicknesses from $80 \mathrm{~nm}$ to $10 \mathrm{~nm}$ were attempted with $\mathrm{RF}$ sputtering, but incomplete coverage lead to decreased shunt resistance. More recently, Heinemann et al., tested $10 \mathrm{~nm}$ to $5 \mathrm{~nm}$ layers of a- $\mathrm{GaO}_{\mathrm{x}}$ with pulsed laser deposition on CIGS absorbers in superstrate configuration. ${ }^{[11]}$

In this aspect, Atomic Layer Deposition (ALD) can provide a unique step forward as it has been proven to be a highly conformal, soft method of deposition for ultra-thin layers. ${ }^{[12]}$ This is also important due to the rough layer of CIGSe in this work. Furthermore, ultra-thin layers of oxides are required for limiting their contribution to series resistance. Typically, relatively high temperatures are required for ALD growth, such as $150{ }^{\circ} \mathrm{C}$ for aluminium oxide and $250{ }^{\circ} \mathrm{C}$ for hafnium oxide used in this study. They can introduce unintentional thermal annealing of CIGS absorbers. In this regard, plasma-enhanced atomic layer deposition (PE-ALD) is a particularly advantageous technique since it enables a low deposition temperature $\left(75^{\circ} \mathrm{C}\right.$ in this work). ${ }^{[13]}$

\section{Experimental Section}

Copper, gallium and indium were co-evaporated on soda lime glass/molybdenum substrates with temperatures of around $1350{ }^{\circ} \mathrm{C}, 1040{ }^{\circ} \mathrm{C}$ and $1000{ }^{\circ} \mathrm{C}$ respectively, with the substrates heated to $550^{\circ} \mathrm{C}$. The CIGS layer was verified by X-ray fluorescence (XRF) to be $1.7 \mu \mathrm{m}$ thick. No gallium grading was used and the ratio of copper to gallium and indium (CGI) was 
approximately $80 \%$ and the ratio of gallium to gallium and indium $(G G I)$ was $30 \%$. All samples were deposited in the same co-evaporation run with very good uniformity.

The substrates were then heated in an annealing step for $15 \mathrm{~min}$ at $460{ }^{\circ} \mathrm{C}$ with $200 \mathrm{sccm}$ of $10 \% \mathrm{H}_{2} \mathrm{Se}$ gas diluted in $\mathrm{N}_{2}$ to create $\mathrm{Cu}(\mathrm{In}, \mathrm{Ga}) \mathrm{Se}_{2}$. In order to ensure that the CIGS surface was oxide free for the ALD deposition, all substrates (including the reference) were subjected to an etch by $30 \% \mathrm{KCN}$ solution for 1 minute. The samples were then sealed in vacuum until the ALD stage.

$\mathrm{GaO}_{\mathrm{x}}$ was deposited via plasma-enhanced ALD at a low temperature of $75{ }^{\circ} \mathrm{C}$ and growth rate of $0.07 \mathrm{~nm} /$ cycle with Trimethylgallium (TMGa) and oxygen plasma as precursors. Its optical bandgap is expected to be $\sim 4.6 \mathrm{eV}$ as observed by ellipsometry in a previous work. ${ }^{[13]}$ This is much higher than the CdS bandgap of $2.4-2.5 \mathrm{eV}$ which causes parasitic absorption. ${ }^{[14]} \mathrm{A}$ metal-insulator-semiconductor (MIS) structure such as in Figure 1 (b) was created with a gallium oxide layer from 256 cycles of ALD. This created approximately $20 \mathrm{~nm}$ of gallium oxide as evidenced in transmission electron microscopy (TEM) (Figure S1 in supporting information). Completed solar cells were created from ultra-thin layers with namely 4, 8, 32 and 64 cycles leading to estimated maximum thicknesses of $0.3 \mathrm{~nm}, 0.6 \mathrm{~nm}, 2.3 \mathrm{~nm}$, and 4.5 $\mathrm{nm}$ of gallium oxide. All the plasma-enhanced atomic layer depositions were carried out at the Australian National University in Canberra. In other test samples, aluminium oxide was deposited via thermal ALD with trimethylaluminium (TMA) (pulse time: $0.016 \mathrm{~ms}$, purge time: $40 \mathrm{~s}$ ) and water (pulse time: $0.03 \mathrm{~ms}$, purge time: $20 \mathrm{~s}$ ) as precursors at a temperature of $150{ }^{\circ} \mathrm{C}$. A linear growth rate of $0.12 \mathrm{~nm} /$ cycle was achieved. Hafnium oxide was similarly deposited via thermal ALD with Tetrakis(ethylmethylamino)hafnium (TEMAH) (pulse time: $0.1 \mathrm{~ms}$, purge time: $35 \mathrm{~s}$ ) and water (pulse time: $0.01 \mathrm{~ms}$, purge time: $30 \mathrm{~s}$ ) as precursors at a temperature of $250{ }^{\circ} \mathrm{C}$ leading to a linear growth rate of $0.11 \mathrm{~nm} /$ cycle.

The substrates were then subjected to chemical-bath deposition of CdS $(\sim 50 \mathrm{~nm})$, sputtering of $100 \mathrm{~nm}$ intrinsic $\mathrm{ZnO}$ and $400 \mathrm{~nm} \mathrm{Al}$-doped $\mathrm{ZnO}$ (total sheet resistance of $50 \mathrm{ohm}$ ) and e-beam 


\section{WILEY-VCH}

deposition of $\mathrm{Ni} / \mathrm{Al} / \mathrm{Ni}$ front grids. Two to five cells of $0.5 \mathrm{~cm}^{2}$ area were mechanically scribed on each substrate.

\section{Capacitance-voltage measurements}

An MIS structure was first created to assess aluminium oxide $(29 \mathrm{~nm})$, gallium oxide $(20 \mathrm{~nm})$ and hafnium oxide $(20 \mathrm{~nm})$ as passivation layers grown by ALD. A schematic of the structure is shown in Figure 1 (b). Capacitance-voltage measurements were made in order to study the density of charges in the oxide layers and the interface trap density. The former was calculated from the flat-band condition. In order to maintain voltage stability of measurements, unanalysed devices were measured in a single sweep under the same temperature and dark conditions. This would exclude any voltage dependent-hysteresis. The normalized capacitance voltage measurements of the three devices at $100 \mathrm{kHz}$ are shown in Figure 2. They indicate flat-band voltages as summarized in Table 1.

The flat-band voltages can be attributed to a density of charges present in the oxide, which can be calculated with the following equation: ${ }^{[15]}$

$\mathrm{Q}_{\mathrm{f}}=\mathrm{C}_{\mathrm{ox}} \frac{\left(\phi_{\mathrm{ms}}-\mathrm{V}_{\mathrm{fb}}\right)}{\mathrm{e}}$

Here $Q_{\text {eff }}$ is the effective charge density in $\mathrm{cm}^{-2}, C_{o x}$ is the oxide capacitance in $\mathrm{F} / \mathrm{cm}^{2}, e$ is elementary charge in coulombs and $\phi_{m s}$ is the work-function difference between the Al metal contact and the CIGS semiconductor. $C_{o x}$ was calculated using the oxide thicknesses mentioned earlier (verified with TEM in the case of $\mathrm{GaO}_{\mathrm{x}}$ ) and estimated dielectric constants of 7.6 for $\mathrm{AlO}_{\mathrm{x}}{ }^{[16]}, 9.2$ for $\mathrm{GaO}_{\mathrm{x}}{ }^{[17]}$ and 18.7 for $\mathrm{HfO}_{\mathrm{x} .}{ }^{[18]}$ It can be noted here that while the dielectric constant of these oxides can slightly vary based on the substrate layer and deposition process, they would not change the order of magnitude of the effective charge density $\left(Q_{e f f}\right)$. The work function difference $\left(\phi_{m s}\right)$ was calculated using the following equations: ${ }^{[15]}$

$\phi_{\mathrm{ms}}=\phi_{\mathrm{m}}-\left(\chi+\frac{E_{g}}{2}+\phi_{\mathrm{fp}}\right)$ 
$\phi_{\mathrm{fp}}=V_{t} \ln \frac{N_{a}}{n_{i}}$

$n_{i}=\sqrt{N_{C} N_{V} e^{-E_{g} / k T}}$

Here $\phi_{m}$ is the work-function of metal aluminium with an average of $4.17 \mathrm{eV} .{ }^{[19]} E_{g}$ is the bandgap of CIGS $(1.15 \mathrm{eV})$, and $\chi$ is electron affinity which was taken to be in the range of 3.9$4.5 \mathrm{eV} .{ }^{[20]} \phi_{f p}$ was calculated for an acceptor concentration of $N_{a}=5 \times 10^{15} \mathrm{~cm}^{-3}$ and intrinsic carrier concentration $\left(n_{i}\right)$ of $7 \times 10^{8} \mathrm{~cm}^{-3} \cdot n_{i}$ was calculated from conduction-band density of

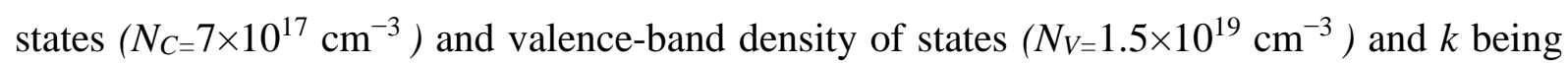
the Boltzmann constant. ${ }^{[7,20]}$

For the range of CIGS electron affinity $(\chi)$ of 3.9-4.5 eV, charge densities $\left(Q_{\text {eff }}\right)$ were calculated as shown in Table 1. In the case of $\mathrm{GaO}_{\mathrm{x}}, Q_{\text {eff }}$ is positive with a values in the range of $1.4 \times 10^{12}$ $\mathrm{cm}^{-2}$ to $5.8 \times 10^{11} \mathrm{~cm}^{-2}$ in case of $\chi=3.9-4.4 \mathrm{eV}$ or weakly negative if CIGS is assumed to have a higher electron affinity. Since the doping levels in CIGSe material of these experiments are comparatively low $\left(10^{15} \mathrm{~cm}^{-3}\right)$, an oxide with positive charge could form a depletion layer and improve charge collection at the front CIGS-CdS interface. This effect has been theoretically studied by Sozzi et al., ${ }^{[6]}$ and Bercegol et al. ${ }^{[7]}$. In contrast, $\mathrm{AlO}_{\mathrm{x}}$ shows high negative charge densities between $-2 \times 10^{11}$ to $-1 \times 10^{12}$ which is consistent with previous observations. ${ }^{[9]}$

A quantitative assessment of the $D_{i t}$ at the oxide-semiconductor interface has not been yet achieved due to the difficulty in conductance measurements at room temperature on these devices. (i.e. no parallel conductance peaks were detected). Nevertheless, we assume that low temperature measurements on these devices could provide more insights on the defect-state densities and distributions within the bandgap, such as in a previous work with $\mathrm{AlO}_{\mathrm{x}}{ }^{[9]}$.

In order to provide at least a qualitative assessment of $D_{i t}$, the slope of the graphs in Figure 2. have been highlighted as dashed lines. According to the Terman method, $C$ - $V$ curves of a MIS capacitor can be interpreted as surface potential $\left(\varphi_{s}\right)$ vs gate voltage curves, which contain information on the interface trap density. Surface potential fluctuations due to presence of 


\section{WILEY-VCH}

interface states will therefore induce a spread in the $C$ - $V$ curves (especially in the depletion regime) as noticed in Figure 2. Gallium oxide clearly shows the most negative slope or in other words, the least $D_{i t}$ among these three samples.

With these encouraging results, solar cells were processed with varying thicknesses of gallium oxide deposited by the low temperature $\left(75^{\circ} \mathrm{C}\right)$ plasma-enhanced ALD on the CIGSe layer. The actual thickness of the gallium oxide layers on CIGSe after deposition and after CdS chemical bath deposition, are as yet, not verifiable as thicknesses less than $1 \mathrm{~nm}$ on such a rough CIGS surface were difficult to detect even with TEM. Nevertheless, all the solar cells were processed together in a stable process line and some differences in photoluminescence and electrical characterization are clearly visible and discussed in the following sections. Minimum temperatures of $127{ }^{\circ} \mathrm{C}-300{ }^{\circ} \mathrm{C}$ are typically required to observe significant thermal annealing effects and hence, we expect $75^{\circ} \mathrm{C}$ to not have any such impact. ${ }^{[21,22,23,24]}$

\section{Photoluminescence}

The passivation layers have a significant effect on photoluminescence $(P L)$ and carrier lifetime. In Figure 3, $P L$ measurements show that all cells were equivalent when the absorber layers were created (dashed lines). In the stage after a $\mathrm{KCN}$ etch, after the deposition of gallium oxide and before $\mathrm{CdS}$ deposition, no significant differences are visible except for the sample with 4 cycles of ALD (dotted lines). The formation of a p-n junction by the deposition of CdS and TCO seems to be necessary to see a higher photoluminescence response and differences between cells (solid lines). This is visible in the reference cell. However, a further increase in response was recorded for the cells with passivation layers starting from 4 cycles to 64 cycles. The highest response was recorded for the cell with 8 cycles of ALD.

An increase in carrier lifetime was also observed with 8 ALD cycles; up to 9 ns as compared to $3 \mathrm{~ns}$ in the reference and other samples (Figure 4). A $2^{\text {nd }}$ order exponential fitting was used for the time-resolved photoluminescence (TRPL) with the equation $\operatorname{IPL}(\mathrm{t})=\mathrm{C}_{1} \mathrm{e}^{-\mathrm{t} / \tau 1}+\mathrm{C}_{2} \mathrm{e}^{-\mathrm{t} / \tau 2}$ 


\section{WILEY-VCH}

(Figure S2 and Table S1 in the supporting information). The value of $\tau_{2}$ has been used as an indication of charge carrier lifetime.

These improvements indicate that the $\mathrm{GaO}_{\mathrm{x}}$ layers are able to passivate charge carrier traps on the top surface which otherwise act as recombination centers.

\section{Electrical performance parameters}

Next, the electrical parameters were characterized. The reduction in recombination is visible in $V_{O C}$ as shown in Figure 5. It shows a clear increasing trend up to an optimum 8 cycles of ALD. The box plots were created with values from 2-5 cells in each case. $J$ - $V$ curves of the best cells from each device are shown in Figure 6. A one-diode model was used for analysis based on the methods by Hegedus et al., and the results are shown in the inset of Figure 6. ${ }^{[25]}$ The calculated dark saturation current $\left(J_{0}\right)$ correlates well with the $V_{O C}$, which are indicators of the total recombination in the cells. In the case of the cell with 8 cycles of ALD, good shunt resistance is also observed as a contributor to $V_{O C}$. The series resistance was higher when 32 cycles of ALD were used. In the sample with 64 cycles of ALD, shunting was observed which may have been caused due to unavoidable physical damage to the sample. This data is nevertheless, included for completeness as its behavior in forward bias is similar to those of the other cells (Figure 6). With all these factors combined, an increasing trend in cell efficiency is observed with up to 8 cycles of ALD (Figure 5) with an absolute increase of $2.6 \%$ in efficiency, $1.04 \mathrm{~mA} / \mathrm{cm}^{2}$ in $J_{S C}, 56.3 \mathrm{mV}$ in $V_{O C}$ and $8.22 \%$ in $F F$ as compared to the reference. One reason for the improved $J_{S C}$ was observed in the $E Q E$ (Figure 7) wherein better response was observed primarily at shorter wavelengths $(500-800 \mathrm{~nm})$.

\section{Summary}

An effective passivation layer can significantly reduce surface recombination and also increase reproducibility in solar cells via a reliable processing step. In addition, plasma-enhanced ALD has showcased a low-temperature of deposition $\left(75^{\circ} \mathrm{C}\right)$ which avoids undesirable annealing 


\section{WILEY-VCH}

effects. ALD growth is currently the most suitable choice for thin-layers of conformal growth on even rough surfaces of photovoltaic materials.

This work presents gallium oxide deposited via Plasma-enhanced ALD as a potential passivation layer for CIGSe. Capacitance-voltage measurements on MIS structures have shown gallium oxide to likely have positive charge densities around $1.4 \times 10^{12}$ to $5.8 \times 10^{11} \mathrm{~cm}^{-2}$ and low $D_{i t}$ as compared to aluminium oxide and hafnium oxide. Improved photoluminescence response was observed with the inclusion of gallium oxide in the cell architecture.

In the case of preliminary solar cell results, it is as yet unclear if ultra-thin layers $(<2 \mathrm{~nm})$ can survive the chemical bath deposition of CdS. Nevertheless, since gallium oxide showcased passivation effects in the $C$ - $V$ and photoluminescence studies, solar cells were fabricated along with a reference in a stable process line. The electrical characterization of these cells did indeed show an absolute increase of $2.6 \%$ in efficiency originating from a substantial increase of 56.3 $\mathrm{mV}$ in $V_{O C}, 1.04 \mathrm{~mA} / \mathrm{cm}^{2}$ in $J_{S C}$, and $8.22 \%$ in $F F$ with a gallium oxide layer as compared to the reference. Therefore as an outlook, future experiments can focus on alternative buffer layers or deposition techniques, point contact openings through thick gallium oxide layers (such as those simulated by Sozzi et al., ${ }^{[6]}$ and Bercegol et al., ${ }^{[7]}$ ) and also low-temperature conductance measurements on MIS structures to quantify $D_{i t}$.

\section{Acknowledgements}

The work published in this paper was supported by the European Research Council (ERC) under the Union's Horizon 2020 research and innovation programme (grant agreement No 715027). The authors would also like to thank Dr. Marcel Simor (Solliance) for the CIGS layer fabrication and Prof. Johan Lauwaert (Universtiy of Ghent) for his guidance on DLTS measurements.

Received: ((will be filled in by the editorial staff))

Revised: ((will be filled in by the editorial staff)) Published online: ((will be filled in by the editorial staff)) 


\section{WILEY-VCH}

\section{References}

[1] P. Jackson, R. Wuerz, D. Hariskos, E. Lotter, W. Witte and M. Powalla, PSS (RRL), 2016, vol. 10, no. 8, p. 583-586.

[2] P. Reinhard, B. Bissig, F. Pianezzi, E. Avancini, H. Hagendorfer, D. Keller, P. Fuchs, M. Döbeli, C. Vigo, P. Crivelli, S. Nishiwaki, S. Buecheler and A. N. Tiwari, Chemistry of Materials, 2015, vol. 27, pp. 5755-5764.

[3] M. Green, Solar Energy Materials and Solar Cells, 2015, vol. 143, pp. 190-197.

[4] B. Vermang, T. J. Wätjen, V. Fjällström, . F. Rostvall, M. Edoff, R. Kotipalli, F. Henry and D. Flandre, Progress in Photovoltaics: Research and Applications, 2014, vol. 22, no. 10, pp. 1023-1029.

[5] M. J. J. V. B. \&. H. C. Edoff, Photovoltaic Specialists Conference (PVSC), 2016 IEEE 43rd, 2016, pp. 3527-3530.

[6] G. Sozzi, S. D. Napoli, R. Menozzi, B. Bissig, S. Buecheler and A. N. Tiwari, Solar Energy Materials \& Solar Cells, 2017, vol. 165, pp. 94-102

[7] A. Bercegol, B. Chacko, R. Klenk, I. Lauermann, M. C. Lux-Steiner and M. Leiro, Journal of Applied Physics, 2016, vol. 119, no. 15, pp..

[8] B. Vermang, V. Fjällström, X. Gao and M. Edoff, IEEE Journal of Photovoltaics, 2014, vol. 4, no. 1, pp. 486-492..

[9] R. Kotipalli, B. Vermang, J. Joel, R. Rajkumar and M. Edoff and D. Flandre, AIP advances, 2015, vol. 5, no. 107101, pp. 1-6.

[10] T. Koida, Y. Kamikawa-Shimizu, A. Yamada, H. Shibata and S. Niki, IEEE Journal of photocvoltaics, 2015, vol. 5, no. 3, pp. 956-961

[11] M. Heinemann, M. F. A. M. van Hest, M. Contreras, J. D. Perkins, A. Zakutayev, C. Kaufmann, T. Unold, D. S. Ginley and J. J. Berry, Physica Status Solidi (a), 2017, vol. 214, no. 5, pp. 1-6.

[12] H. B. Profijt, S. E. Potts, M. C. M. Van de Sanden and W. M. M. \& Kessels, Journal of Vacuum Science \& Technology A: Vacuum, Surfaces, and Films, 2011, vol. 29, no. 5, p. 050801

[13] T. G. Allen, M. Ernst, C. Samundsett and A. Cuevas, IEEE Journal of Photovoltaics, 2015 vol. 5, no. 6, pp. 1586-1590.

[14] J. Dona and J. Herrero, J. Electrochem. Soc., 1997, vol. 144, pp. 4081-4091.

[15] D. Schroder, Semiconductor material and device characterization, Hoboken: John Wiley \& Sons Inc, 2006.

[16] M. Groner, J. Elam, F. Fabreguette and S. George, Thin Solid Films, 2002, vol. 413, no. 1-2, pp. 186-197.

[17] D.W. Choi, K.B. Chung and J.S. Park, Thin Solid Films, 2013, vol. 546, pp. 31-34.

[18] J. Robertson, Journal of Applied Physics, 2008, vol. 104, no. 12, p. 124111.

[19] W. M. Haynes, CRC handbook of chemistry and physics, Boca raton: CRC press, 2014.

[20] C. Frisk, C. Platzer-Björkman, J. Olsson, P. Szaniawski, J. T. Wätjen, V. Fjällström, P. Salomé and M. Edoff, Journal of Physics D: Applied Physics, 2014, vol. 47, no. 48, pp. $1-12$.

[21] E. Moons, D. Gal, J. Beier, G. Hodes, D. Cahen, L. Kronik, B. L., B. Mishori, Y. Shapira, D. Hariskos and H. Schock, Solar energy materials and solar cells, 1996, vol. 43, no. 1, pp. 73-78.

[22] Y.-D. Chung, D.-H. Cho, N.-M. Park, K.-S. Lee and J. Kim, Current Applied Physics, 2011, vol. 11, no. 1, pp. S65-S67. 


\section{WILEY-VCH}

[23] D. S. Chen, ,. J. Yang, Z. B. Yang, F. Xu, H. W. Du and Z. Q. and Ma, Materials Research Bulletin, 2014, vol. 54, pp. 48-53,.

[24] T. Sakurai, N. Ishida, S. Ishizuka, M. M. Islam, A. Kasai, K. Matsubara, K. Sakurai, A. Yamada, K. Akimoto and S. and Niki, Thin Solid Films, 2008, vol. 516, no. 20, pp. 7036-7040.

[25] S. S. Hegedus and W. N. Shafarman, Progress in photovoltaics: Research and applications, 2004, vol. 12, pp. 155-176.

Figure 1. Schematics of the solar cell architecture with the gallium oxide passivation layer shown between CIGS and CdS (a) and Metal-insulator-semiconductor structure used for capacitance-voltage measurements (b) (not to scale)

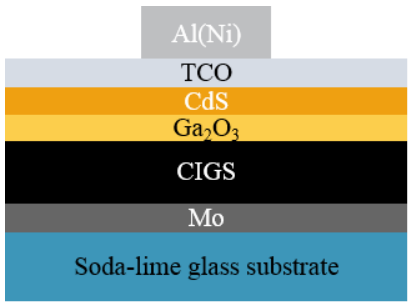

(a)

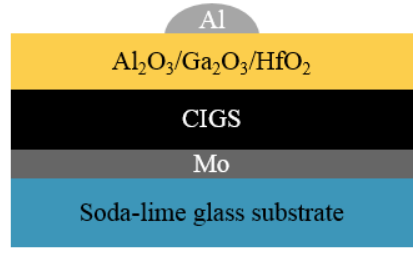

(b)

Figure 2. Normalized capacitance-voltage curves at $100 \mathrm{kHz}$ for MIS structures with $\mathrm{AlO}_{\mathrm{x}}$, $\mathrm{GaO}_{\mathrm{x}}$ and $\mathrm{HfO}_{\mathrm{x}}$

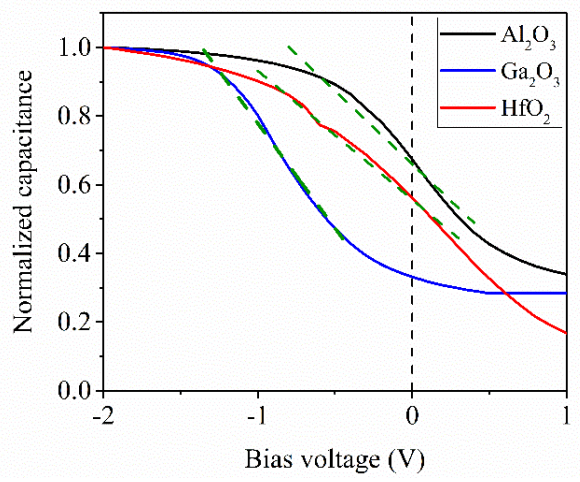

Figure 3. Photoluminescence measurements show the similarity between as-deposited absorbers (dashed lines) and differences in the completed cells (solid lines) possibly arising from $\mathrm{GaO}_{\mathrm{x}}$ deposition. 


\section{WILEY-VCH}

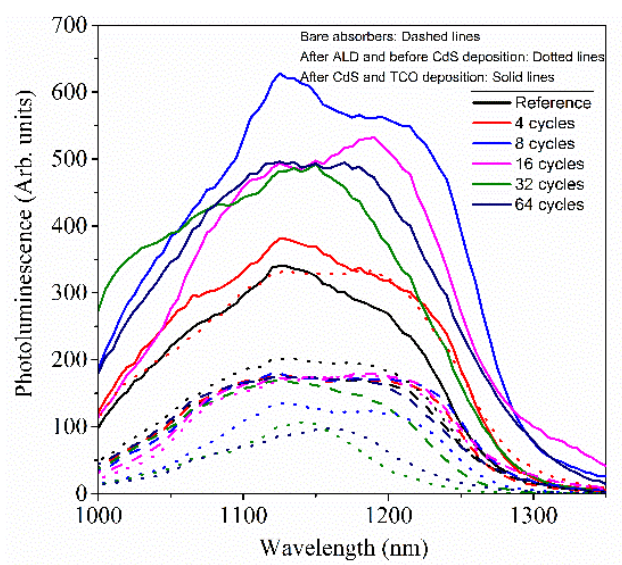

Figure 4. Higher charge carrier lifetime was observed with 8 cycles of ALD as compared to the reference and other samples.

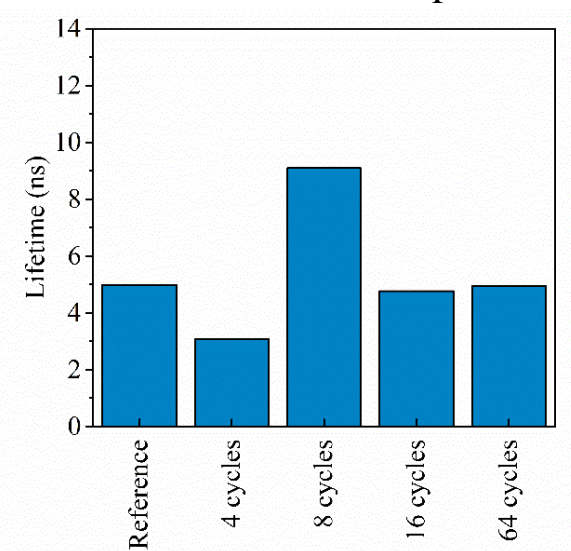

Figure 5. Electrical parameters of completed solar cells (2-5 cells in each case) show optimal values with 8 cycles of ALD 


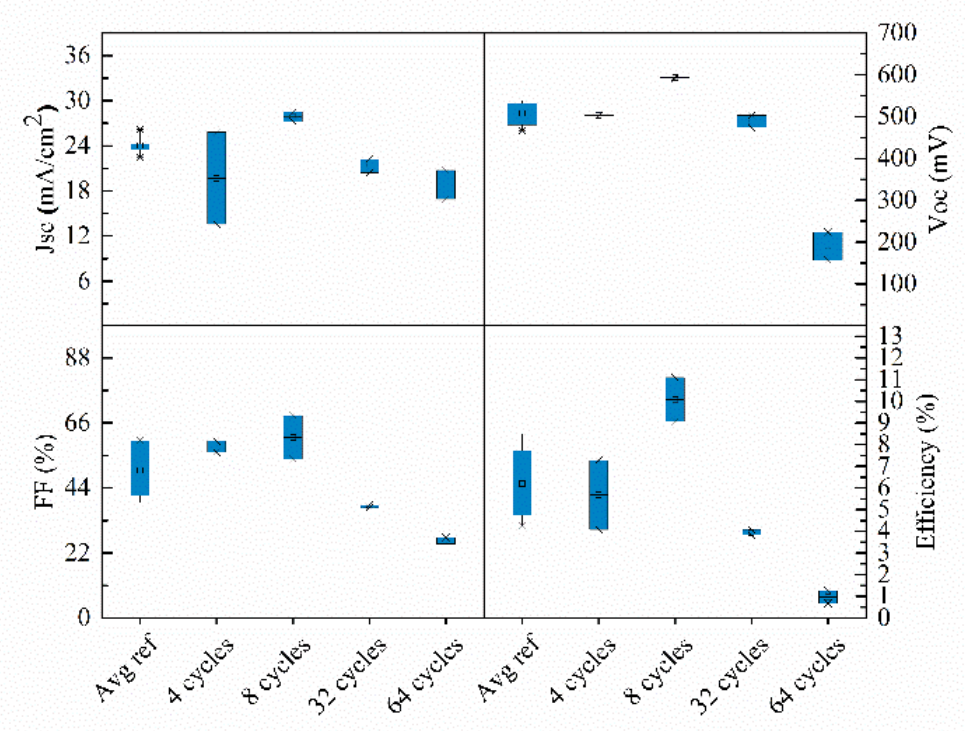

Figure 6. $J-V$ curves of the best cells from each device show the reduction in recombination and increased shunt resistance with 8 cycles of ALD as compared to the reference. An increase in series resistance is visible with 32 cycles of ALD. A one-diode model was used for analysis according to the methods by Hegedus et al. ${ }^{[21]}$

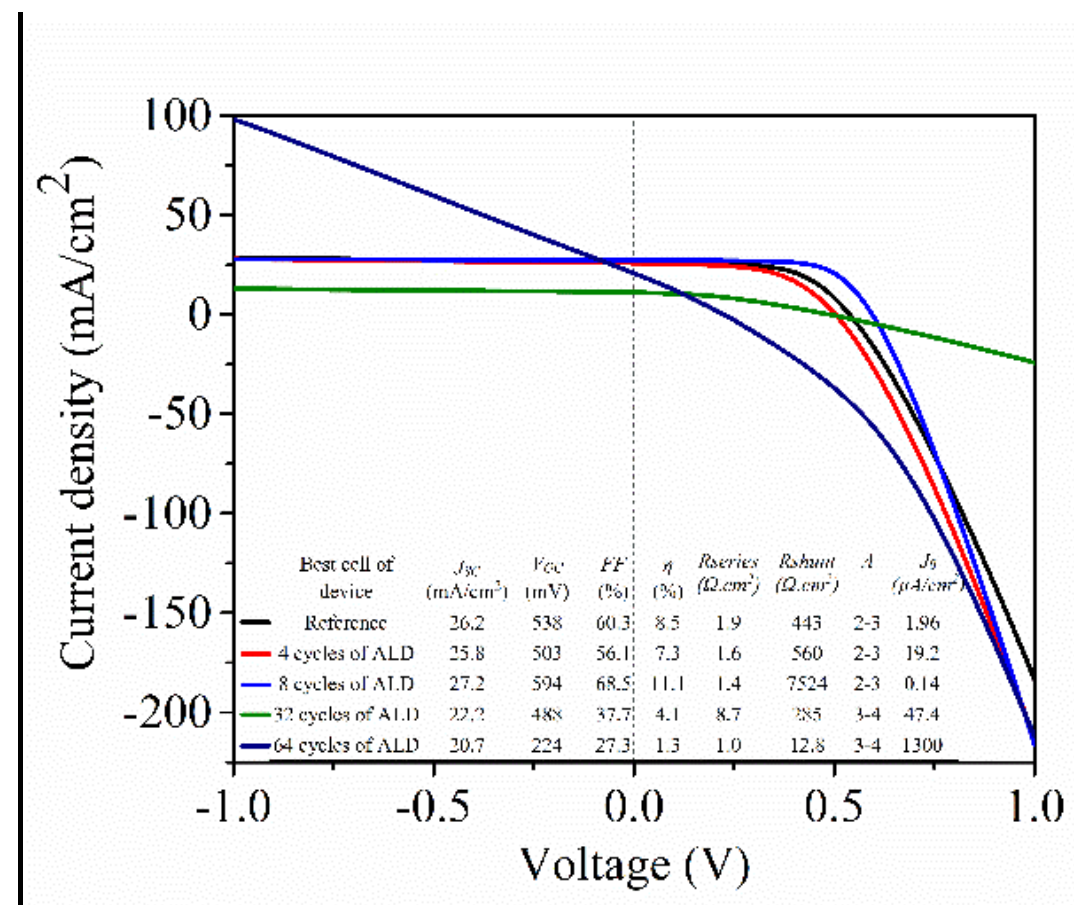

Figure 7. EQE of the cell with 8 cycles of ALD was observed to be better than that of the reference cell at the shorter wavelengths $(500-800 \mathrm{~nm})$. 


\section{WILEY-VCH}

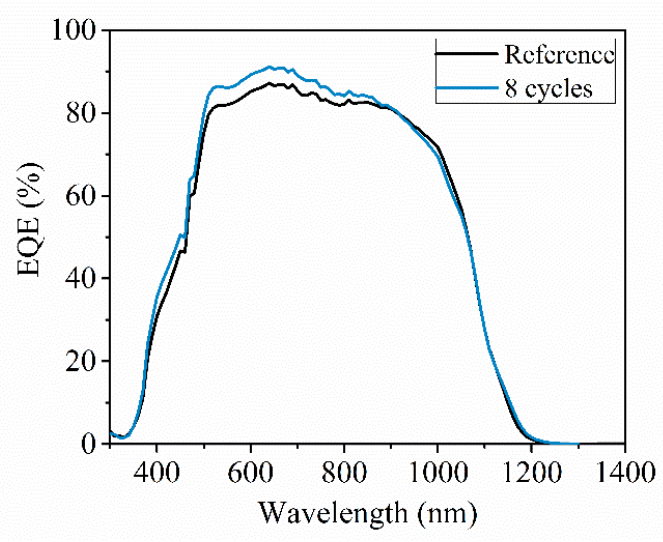

Table 1. Flat-band voltage calculated from $C-V$ measurement

\begin{tabular}{|c|c|c|c|c|c|}
\hline Oxide layer & $\begin{array}{l}\text { Flat-band } \\
\text { Voltage }\left(V_{t b}\right) \\
\text { (V) }\end{array}$ & $\begin{array}{c}\text { Oxide } \\
\text { capacitance }\left(C_{o x}\right) \\
\left(\mathrm{F} / \mathrm{cm}^{2}\right)\end{array}$ & $\begin{array}{c}\text { Charge } \\
\text { density } \\
\left(Q_{\text {eff }}\left(\mathrm{cm}^{-2}\right)\right. \\
\text { with } X \mathrm{CIGS}= \\
3.9 \mathrm{eV} \\
\end{array}$ & $\begin{array}{c}\text { Charge } \\
\text { density } \\
\left(Q_{\text {eff }}\right)\left(\mathrm{cm}^{-2}\right) \\
\text { with } X_{\mathrm{CIGS}}= \\
4.2 \mathrm{eV}\end{array}$ & $\begin{array}{c}\text { Charge } \\
\text { density } \\
\left(Q_{\text {eff }}\left(\mathrm{cm}^{-2}\right)\right. \\
\text { with XCIGs } \\
4.5 \mathrm{eV} \\
\end{array}$ \\
\hline $\mathrm{AlO}_{x}$ & -0.5 & $2.7 \times 10^{-7}$ & $-2.0 \times 10^{11}$ & $-6.4 \times 10^{11}$ & $-1.1 \times 10^{12}$ \\
\hline $\mathrm{GaO}_{\mathrm{x}}$ & -1.2 & $4.1 \times 10^{-7}$ & $1.4 \times 10^{12}$ & $5.8 \times 10^{11}$ & $-1.8 \times 10^{11}$ \\
\hline $\mathrm{HfO}_{x}$ & -1 & $8.3 \times 10^{-7}$ & $1.3 \times 10^{12}$ & $-2.1 \times 10^{11}$ & $-1.76 \times 10^{12}$ \\
\hline
\end{tabular}

Table of contents entry: This work proposes gallium oxide as a surface passivation layer on the photovoltaic material in $\mathrm{Cu}(\mathrm{In}, \mathrm{Ga}) \mathrm{Se}_{2}$ (CIGS) solar cells. A metal-insulator-semiconductor (MIS) structure is used to compare aluminium oxide, gallium oxide and hafnium oxide for this purpose. Solar cells fabricated with gallium oxide deposited between the CIGS and CdS buffer layer interface, show better performance than reference cells.

Keywords: CIGS solar cells; surface passivation; gallium oxide; plasma-enhanced atomic layer deposition

S.Garud, N. Gampa, T. Allen, Dr. R. Kotipalli, Prof. D. Flandre, Dr. M. Batuk ${ }^{5}$, Prof. J. Hadermann, Dr. M. Meuris, Prof. J. Poortmans, Prof. A.H.M. Smets, Prof. B. Vermang*

Surface passivation of CIGS solar cells using gallium oxide

ToC figure:

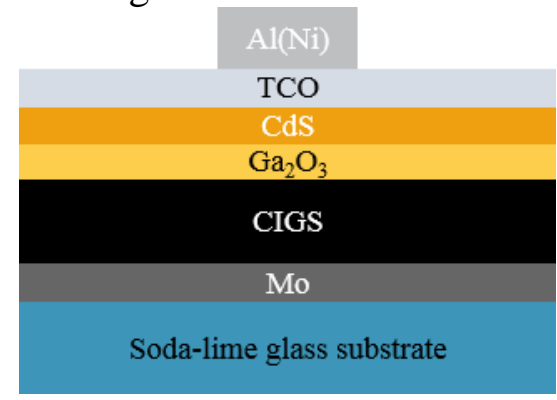




\section{WILEY-VCH}

Copyright WILEY-VCH Verlag GmbH \& Co. KGaA, 69469 Weinheim, Germany, 2016.

\section{Supporting Information}

Figure S1 Overview image from high-angle annular dark-field imaging- scanning transmission electron microscope (HAADF-STEM) (a), individual elemental maps (in counts) (b-f), and mixed $\mathrm{Cu} / \mathrm{In} / \mathrm{Ga} / \mathrm{Se}$ map (g). Gallium oxide deposited by plasma-enhanced atomic layer deposition on a rough CIGS surface shows highly conformal growth of $20 \mathrm{~nm}$ thickness even in cracks.

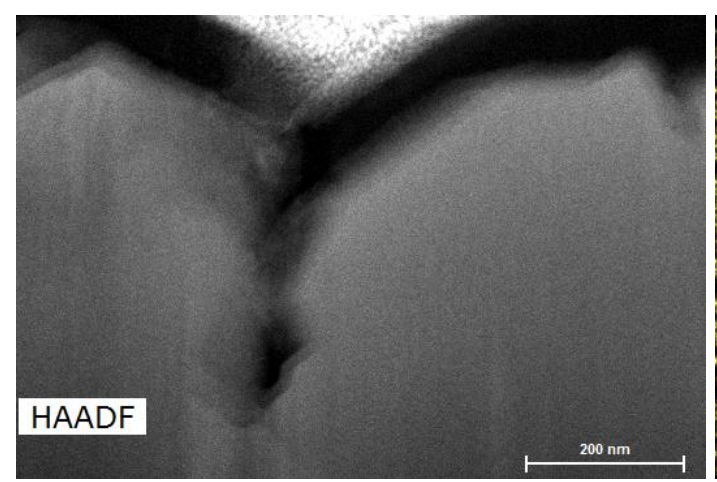

(a)

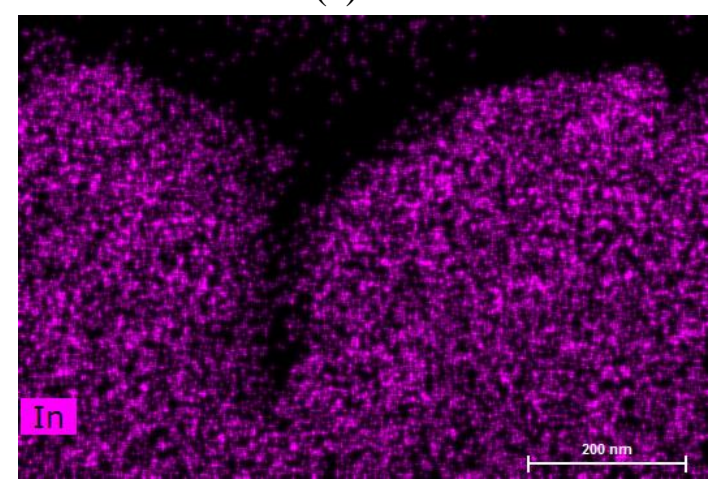

(c)

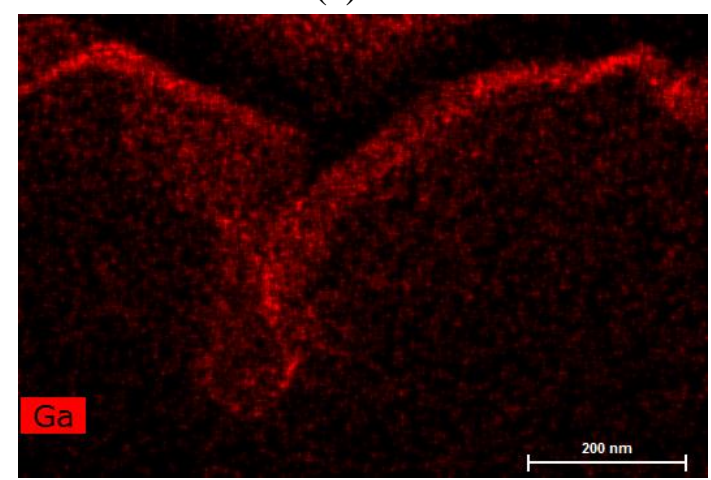

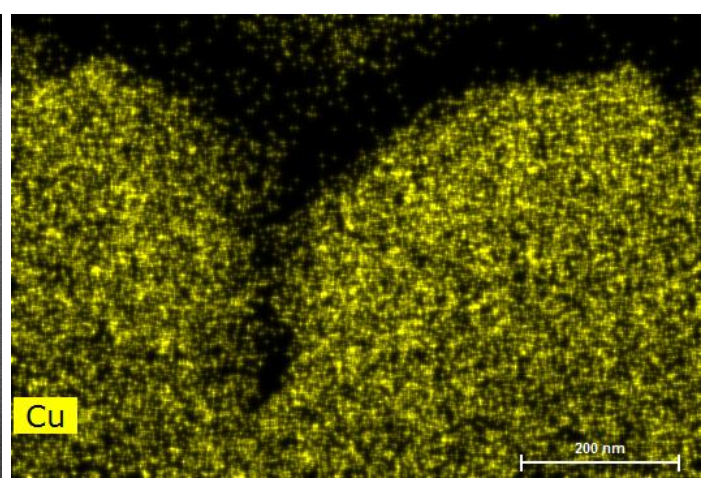

(b)

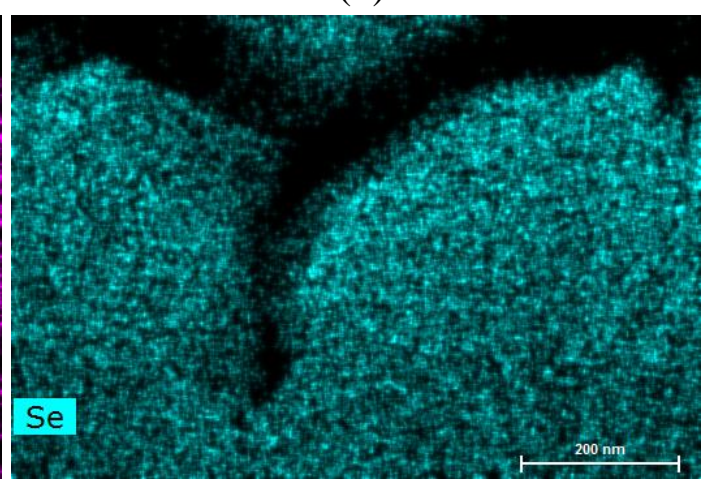

(d)

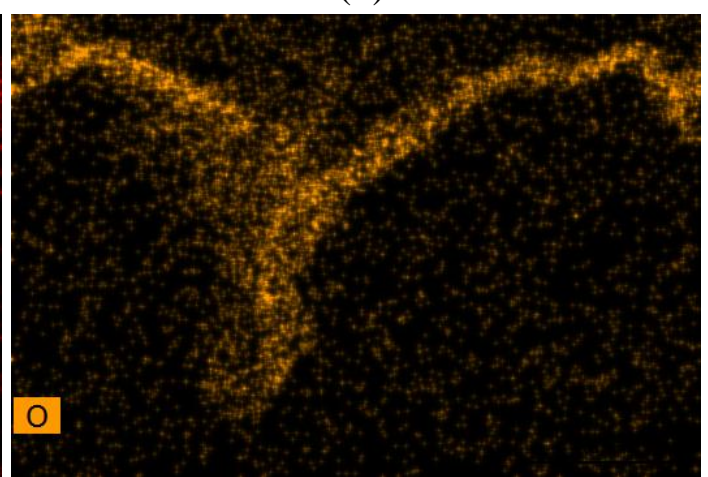




\section{WILEY-VCH}

(e)

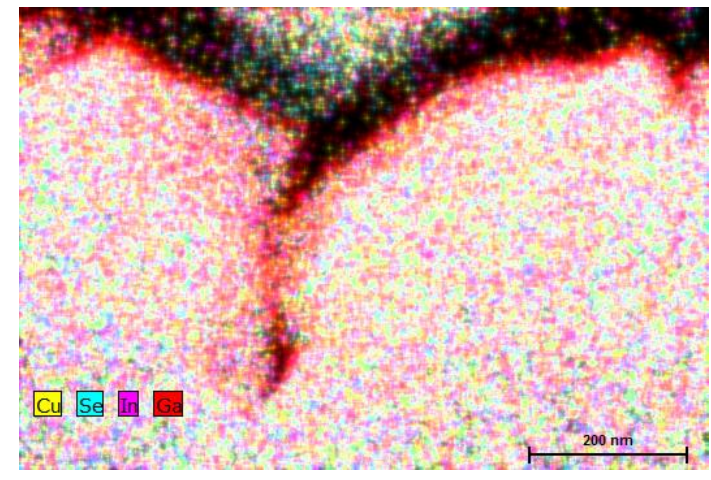

$(\mathrm{g})$ (f)

Figure S2 The time-resolved photoluminescence (TRPL) of each cell shown here was fitted with a $2^{\text {nd }}$ order exponential equation (Please see Table S1).

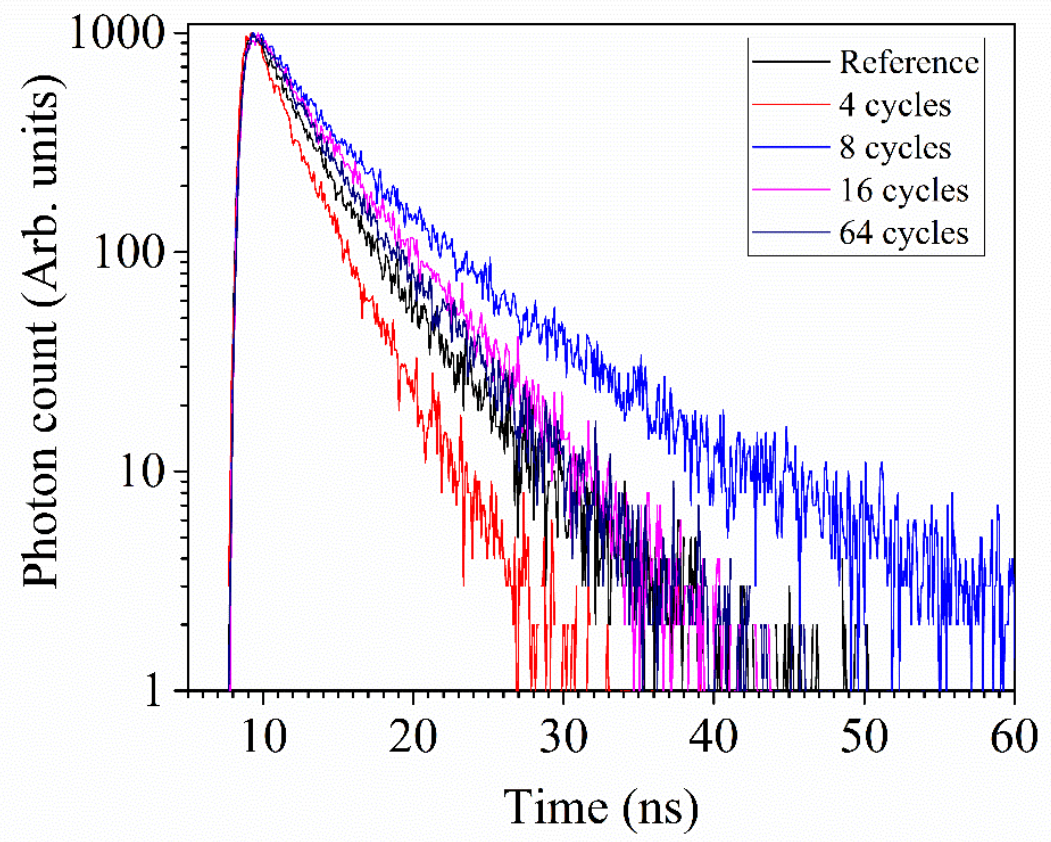

Table S1 A $2^{\text {nd }}$ order exponential fitting was used for the time-resolved photoluminescence (TRPL) with the equation $\operatorname{IPL}_{\mathrm{PL}}(\mathrm{t})=\mathrm{C}_{1} \mathrm{e}^{-\mathrm{t} / \tau 1}+\mathrm{C}_{2} \mathrm{e}^{-\mathrm{t} / \tau 2}$. The value of $\tau_{2}$ has been shown as an indication of charge carrier lifetime in Figure 4.

\begin{tabular}{cccc}
\hline Sample & CHI & $\mathrm{t} 1$ & $\mathrm{t} 2$ \\
\hline Reference & 1.05 & 2.3 & 5 \\
4 cycles & 0.9 & 1.2 & 3.1 \\
8 cycles & 1.2 & 3.4 & 9.1 \\
16 cycles & 1.2 & 1.3 & 4.8 \\
64 cycles & 1.1 & 2.3 & 4.9 \\
\hline
\end{tabular}


WILEY-VCH 